\title{
Acrorenal Mandibular Syndrome: A Case Report
}

BS NAHER

(J Banagladesh Coll Phys Surg 2015; 33: 95-97)

\section{Introduction:}

Acral (limb) and renal anomalies occur together as a single developmental field defect $(\mathrm{DFC})^{1}$ or as components of several malformation syndromes. The embryogenesis of that defect was studied experimentally by $\mathrm{Lash}^{2}$ and the developmental relationship between kidneys and limbs has been reviewed by Buchta ${ }^{3}$ and Gilbert $^{4}$. In 1980, Halal et al. first described the association of bilateral split foot malformation, severe mandibular hypoplasia and bilateral renal malformation in female sibs born to consanguineous French- Canadian parents. Bilateral renal agenesis was found in one sib and bilateral polycystic kidneys in the other ${ }^{5}$. These authors proposed the name acro-renal-mandibular syndrome (ARMS) for the condition and considered it most likely that the mechanism of inheritance was autosomal recessive.

The acral anomalies consist of split hand/ split foot, varying combination of oligodactyly, ectrodactyly, syndactyly, brachydactyly, polydactyly or fusion of carpal, tarsal, metatarsal bones of hands and feet. Urinary tract dysplasias are renal agenesis, duplication, ureteral hypoplasia, polycystic kidneys, hydronephrosis and bladder neck obstruction.

The purpose of this paper to report a newborn with acral (polydactyly) and renal malformation (polycystic kidney) rather than split hands/ feet (acral) malformation, the most typical digital malformation in acrorenal mandibular syndrome as much is not known about the occurrence of such case in Bangladesh.

\section{Case Report:}

A 10 day old male baby, $1^{\text {st }}$ issue of consanguineous parents hailing from Keranigang, Dhaka was admitted into Sir Salimullah Medical College and Mitford Hospital on $2^{\text {nd }}$ November, 2013 with the complaints of inability

Address of Correspondence: Dr. Begum Sharifun Nahar, Associate Professor, Department of Neonatology, Sir Salimullah medical College and Mitford Hospital, Dhaka. Cell: 01819263555, 9660446(Res)

Received: 9 January, 2014

Accepted: 20 August, 2014 to suckle breast properly and limitation in upper limb movement since birth. Mother Farzana 20 year old nondiabetic, normotensive, nonasthmatic had good antenatal health. She received one dose of tetanus toxoid during her antenatal check up. There was no history of taking any drug other than vitamins and folic acid in pregnancy. She did not suffer from fever or rash at any time of gestational period. Her pregnancy was uneventful up to 39 weeks of gestation. Then she delivered a male baby per vaginally in the hospital. Baby was mildly asphyxiated at birth. There was no history of prelacteal feeding. Baby was put to breast within one hour of birth but he was not able to feed properly and mother noticed that the lower part of the face was depressed (Fig. 1). On examination, the baby was pink

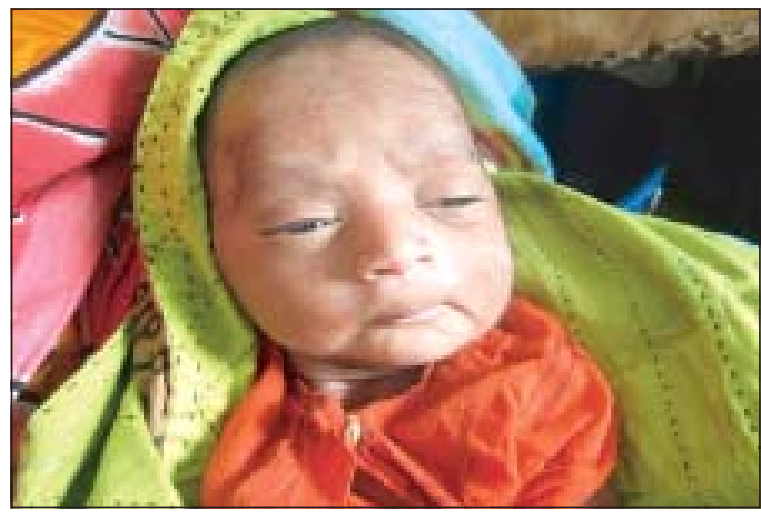

Fig.-1: Showing right sided mandibular hypoplasia

in colour, weight was $2.3 \mathrm{~kg}$, length $43 \mathrm{~cm}$ and occipitofrontal circumference was $32 \mathrm{~cm}$. All vital parameters were normal. High arched palate and polydactyly was present in both upper and lower extremities (Fig. 2 and 3). Extension of elbow joints was restricted on both sides. Air entry was good on both sides of the chest. Heart sounds were normal. Abdomen was soft, liver and spleen were normal in size but the left kidney was bimanually palpable and ballotable. Spine was normal.

On investigation, Haemoglobin was $19 \mathrm{gm} / \mathrm{dl}$, TC of WBC was13000/cmm, platelet count was 380,000/cmm. Differential count of WBC and CRP was normal. Blood 


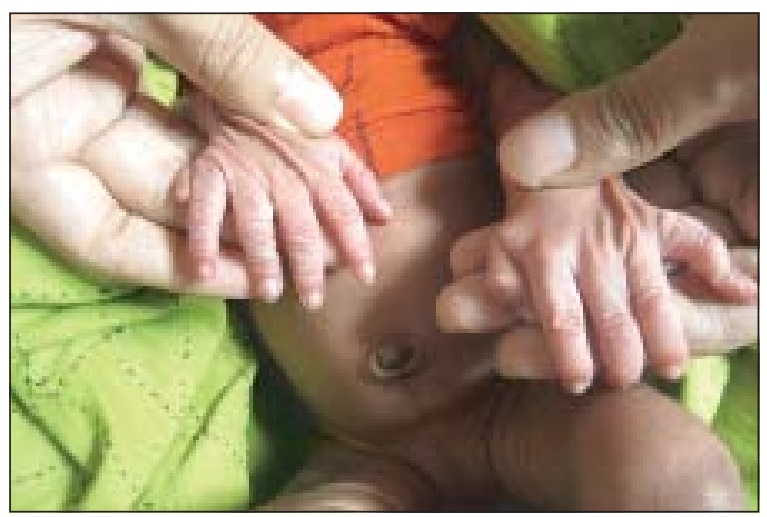

Fig.-2: Showing polydactyly of hands

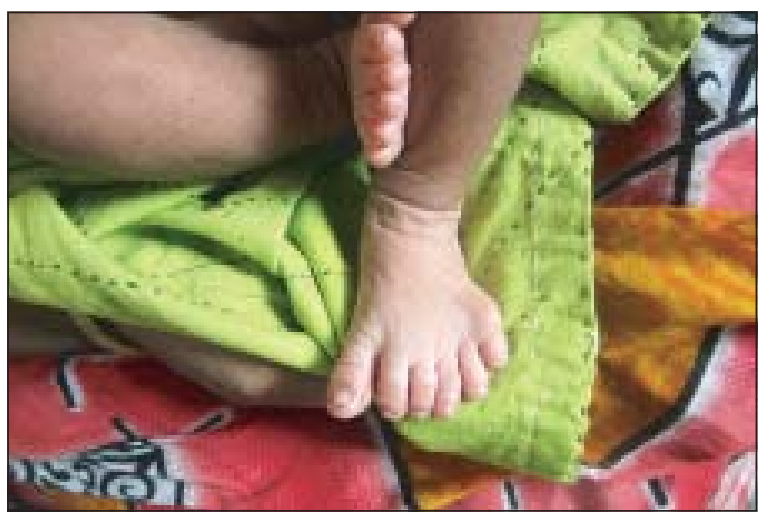

Fig.-3: Showing bilateral polydactyly of feet

culture showed no growth of any organism. Doppler echocardiography was also normal. Ultrasonography of brain was normal but whole abdomen revealed bilateral echogenic kidneys with multiple tiny cysts in both kidneys (Fig. 4). Serum creatinine was $3 \mathrm{mg} / \mathrm{dl}$ but

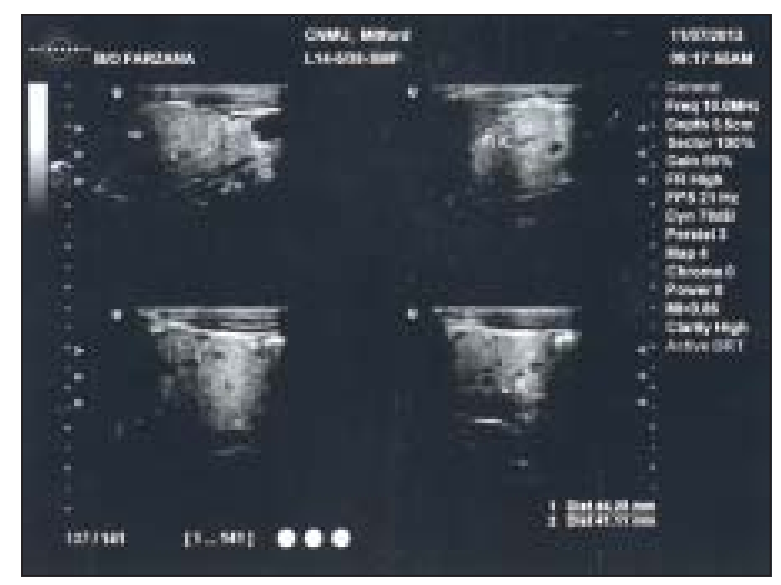

Fig.-4: Bilateral echogenic kidneys with multiple tiny cysts in both kidneysReferences: electrolyte was within normal level. Skeletal survey was done and was unremarkable. So on the basis of hypoplastic mandible, high arched palate, polydactyly, cystic kidneys, flexion contractures of upper limb she was diagnosed as acrorenal mandibular syndrome. We managed the baby by helping her in breast feeding in proper technique. We consulted with paediatric nephrologists and followed their advice. We also consulted with the paediatric surgeon regarding polydactyly and according to their suggestion we advised her to come for follow up visit in paediatric surgery out patient department later on. We counseled the parents regarding the risk of recurrence which is $25 \%$ and offered prenatal diagnosis using ultrasonographic examination.

\section{Discussion:}

The association between skeletal and renal anomalies is well known. This association is seen in a very heterogeneous group of acrorenal syndrome ${ }^{6}$.The ARM syndrome is also known as acrorenal-uterine-mandibular syndrome or split hand and split foot syndrome with mandibular hypoplasia.

The pathogenesis has been linked to an abnormal epithelial-mesenchymal interaction during embryonic development ${ }^{7}$. Such interaction is obviously crucial to the formation of the apical-ectodermal ridge and subsequent limb development and to the development of ureteric bud. This is also involved in the morphogenesis of the palate, jaw, skin derivatives, the mammary glands, the paramesonephric ducts and the eye. Thus the major anomalies found in this patient appear to share a pathogenetic relationship.

Although the most typical limb deficiencies (LD) for the acrorenal syndrome is split hand/ split foot ${ }^{8}$; Kroes et al. ${ }^{6}$ did not support this suggestion as several digital malformation like polydactyly, syndactyly, ectrodactyly other than split hand/foot are also observed in cases of acrorenal syndrome indicating clinical/ phenotypic variability in their reports.

Our case report suggests that bilateral symmetrical polydactyly of both hands and feet is a part of ARUMS/ ARMS. This case is born to consanguineous parents. So the mechanism of inheritance is thought most likely to be autosomal recessive as is seen in the reports by Kroes ${ }^{6}$. 


\section{References:}

1. Dieker H, Opitz JM. Associated acral and renal malformation. Birth Defects Orig Artic Ser V. 1969; 3: 68-77.

2. Lash JW. Normal embryology and teratogenesis. Am J Obst Gynecol 1964; 90; 1193-1207.

3. Buchta RM, Viseskul C, Gilbert EF, Sarto GE, Opitz JM. Familial bilateral renal agenesis and hereditary renal adysplasia. Z Kinderheilkd. 1973 Aug 31;115(2):111129. [PubMed]

4. Gilbert EF, Opitz JM.; Latteinte in the renal hereditary malformation syndromes. Ch 44 In Hamburger et al (eds);
Addresses Nephrologic, Volume 2 Paris. Flammarion 1979 Pp 936-70.

5. Halal F, Desgranges M-F, Leduc B, Theoret G, Bettez P. Acro -renal-mandibular syndrome. Am J Med Genet 1980; 5: $277-84$

6. Kroes HY, Olney RS, Rosano A, Liu Y, Castilla EE, Cocchi $\mathrm{G}$ et al. Renal defects and limb deficiencies in 197 infants: Is it possible to define the acrorenal syndrome? Am J Med Genet 2004; 129: 149-55.

7. Evans JA, Phillips S, Reed M, Chodirker BN, Severe acrorenal-uterine-mandibular syndrome. Am J Med Genet 2000; 93: 67-73.

8. Houlston R, Macdermot K. Acrorenal syndrome: Further observations. Clinic Dysmorphol 1992; 1: 23-28. 